RAND RESEARCH AREAS CHILDREN AND FAMILIES EDUCATION AND THE ARTS ENERGY AND ENVIRONMENT HEALTH AND HEALTH CARE INFRASTRUCTURE AND TRANSPORTATION INTERNATIONAL AFFAIRS LAW AND BUSINESS NATIONAL SECURITY POPULATION AND AGING PUBLIC SAFETY SCIENCE AND TECHNOLOGY TERRORISM AND HOMELAND SECURITY
This fact sheet is part of the RAND Corporation research brief series. RAND fact sheets summarize published, peerreviewed documents.

Headquarters Campus 1776 Main Street P.O. Box 2138 Santa Monica, California 90407-2138

TEL 310.393 .0411

FAX 310.393 .4818

( RAND 2010

\section{Post-Katrina Project Demonstrates a Rapid, Participatory Assessment of Health Care and Develops a Partnership for Post-Disaster Recovery in New Orleans}

$\mathrm{H}$ urricane Katrina and levee failures disrupted health care access for hundreds of thousands of Americans. While federal efforts have since improved aspects of primary care, research has documented high levels of unmet health needs in Katrina-affected communities.

Research and policy efforts that address health care concerns among vulnerable populations in post-disaster settings present important opportunities for community-directed recovery. REACH NOLA (Rapid Evaluation and Action for Community Health in New Orleans, Louisiana) partnered with New Orleans-area nongovernmental organizations and academic institutions and, one year after Katrina, engaged communities in an assessment of health priorities. Thirty nominees representing community health organizations and the general public were interviewed, and four grassroots discussion groups were held to assess perceptions of the disaster's impacts on health care access. The goals were to inform the policy process and build capacity for recovery planning. Findings were shared at a public community conference in which participants provided feedback and developed recovery-relevant action steps.

Project data revealed three main themes:

- Health care access challenges. Interviewees identified major challenges, including widespread closures of facilities, displacement of the health care workforce, and disruptions of physician-patient relationships. Access was particularly limited for uninsured residents who relied on the now-closed state hospital for care and for persons seeking specialists, such as psychiatrists or oncologists.

- Unmet needs of specific vulnerable populations. Multiple vulnerable populations faced critically limited access to necessary health care services in the year following Hurricane Katrina. They included elderly, HIV-positive, tuberculosis-positive, and mentally ill patients, as well as women seeking obstetrical services.

- Opportunities, resources, and adaptations to improve community recovery. Interviewees cited many reasons to be hopeful about the future of recovery, including visionary leadership, government transparency, and dialogue among returning citizens and policymakers. They noted promising collaborations among community groups, private-sector interests, government agencies, and academia.

This study is, to its authors' knowledge, the first community-based participatory research project to engage a diverse group of affected community members in the design and conduct of an assessment of health care needs following a major disaster, as well as in the interpretation and dissemination of the results. This assessment provided new information on community members' priorities, documented

Continued on back

This fact sheet is based on Springgate BF, Allen C, Jones C, Lovera S, Meyers D, Campbell L, Palinkas LA, and Wells KB, "Rapid Community Participatory Assessment of Health Care in Post-Storm New Orleans," American Journal of Preventive Medicine, Vol. 37, No. 6, Supp. 1, December 2009, pp. s237-s243. 
significant public health concerns relevant to disaster preparedness and community health, and produced a sustainable community-academic partnership dedicated to improving access to quality health care, with implications for future disaster preparedness policy, programs, and research. The project and subsequent developments reveal the feasibility of such a community-academic partnered approach to formulate and address disaster-recovery goals.

\section{Office of Congressional Relations ｜ 703-413-1100 x5320 | ocr@rand.org ｜ www.rand.org/congress}

This fact sheet describes work done by the RAND Gulf States Policy Institute in collaboration with RAND Health.

This fact sheet was written by Shelley Wiseman. The RAND Corporation is a nonprofit research organization providing objective analysis and effective solutions that address the challenges facing the public and private sectors around the world. RAND's publications do not necessarily reflect the opinions of its research clients and sponsors. RAND $^{\circledR}$ is a registered trademark.

\section{RAND Offices}

Santa Monica, CA • Washington, DC • Pittsburgh, PA • New Orleans, LA/Jackson, MS • Boston, MA • Doha, QA • Cambridge, UK • Brussels, BE 
A study by RAND Health

THE ARTS

CHILD POLICY

CIVIL JUSTICE

EDUCATION

ENERGY AND ENVIRONMENT

HEALTH AND HEALTH CARE

INTERNATIONAL AFFAIRS

NATIONAL SECURITY

POPULATION AND AGING

PUBLIC SAFETY

SCIENCE AND TECHNOLOGY

SUBSTANCE ABUSE

TERRORISM AND HOMELAND SECURITY

TRANSPORTATION AND

INFRASTRUCTURE

WORKFORCE AND WORKPLACE
This PDF document was made available from www.rand.org as a public service of the RAND Corporation.

This product is part of the RAND Corporation research brief series. RAND research briefs present policy-oriented summaries of individual published, peerreviewed documents or of a body of published work.

The RAND Corporation is a nonprofit research organization providing objective analysis and effective solutions that address the challenges facing the public and private sectors around the world.

\section{Support RAND}

$\underline{\text { Browse Books \& Publications }}$

Make a charitable contribution

\section{For More Information}

\author{
Visit RAND at www.rand.org \\ Explore the RAND Gulf States Policy Institute \\ View document details
}

Limited Electronic Distribution Rights

This document and trademark(s) contained herein are protected by law as indicated in a notice appearing later in this work. This electronic representation of RAND intellectual property is provided for non-commercial use only. Unauthorized posting of RAND PDFs to a non-RAND Web site is prohibited. RAND PDFs are protected under copyright law. Permission is required from RAND to reproduce, or reuse in another form, any of our research documents for commercial use. For information on reprint and linking permissions, please see $\underline{\text { RAND Permissions. }}$ 